\title{
ASSURE-CSU: a real-world study of burden of disease in patients with symptomatic chronic spontaneous urticaria
}

Karsten Weller ${ }^{1 *}$, Marcus Maurer ${ }^{1}$, Clive Grattan², Alla Nakonechna ${ }^{3}$, Mohamed Abuzakouk ${ }^{3}$, Frédéric Bérard4, Gordon Sussman", Ana M. Giménez-Arnau', Javier Ortiz de Frutos ${ }^{7}$, André Knulst ${ }^{8}$, G. Walter Canonica ${ }^{9}$, Kelly Hollis ${ }^{10}$, Doreen McBride ${ }^{11}$ and Maria-Magdalena Balp ${ }^{12}$

\begin{abstract}
Background: Chronic spontaneous urticaria (CSU) formerly known as chronic idiopathic urticaria (CIU) is a severe and distressing skin condition that remains uncontrolled in approximately one half of patients, despite the use of licensed, recommended doses of modern, second-generation $\mathrm{H}_{1}$-antihistamines. So far, the humanistic, societal and economic burden of CSU/CIU has not been well quantified. Therefore it is important to broaden our understanding of how CSU/CIU impacts patients, society, and healthcare systems, by determining the disease burden of CSU/CIU and the associated unmet need; as well as to further guide the use of new treatments in an efficient and cost-effective manner.

Methods: ASSURE-CSU is an observational, multicenter study being conducted in the UK, Germany, Canada, France, Italy, Spain, and The Netherlands. The study comprises a retrospective medical chart review in conjunction with patient surveys (including validated tools for assessment of disease impact) and an 8-day patient diary. The primary objectives of the study are to describe patient demographics, medical history, treatments, and healthcare resource utilization based on medical-record data and to assess the impact of disease, healthcare resource utilization, work days missed, and productivity loss based on patient-reported data. Approximately 700 patients (aged $\geq 18$ years) will be enrolled who have CSU/CIU despite currently receiving treatment, and have had persistent symptoms for at least 12 months. Data will be collected retrospectively for the 12 months ( \pm 1 month) prior to enrolment wherever possible, and prospectively for the week following enrolment.

Discussion: ASSURE-CSU will be the first study to examine the economic and humanistic burden of disease in patients diagnosed with CSU/CIU who are symptomatic despite treatment. By combining retrospective evaluation of medical records with prospective patient surveys and 8-day diaries, across seven different countries, the ASSURE-CSU study will contribute to a better understanding and acknowledgement of the burden of disease in patients with symptomatic chronic spontaneous urticaria.
\end{abstract}

Keywords: Chronic spontaneous urticaria, Chronic idiopathic urticaria, Angioedema, Disease burden, Humanistic burden, Economic cost, Presenteeism, Absenteeism, Observational

\footnotetext{
* Correspondence: karsten.weller@charite.de

'Allergie-Centrum-Charité, Department of Dermatology and Allergy,

Charité - Universitätsmedizin Berlin, Charitéplatz 1, D-10117 Berlin, Germany

Full list of author information is available at the end of the article
} 


\section{Background}

Urticaria is characterized by the sudden appearance of hives, angioedema or both [1]. Chronic spontaneous urticaria (CSU), formerly known as chronic idiopathic urticaria (CIU) is defined by the spontaneous development of itchy hives and/or angioedema that reoccur for at least 6 weeks due to known or unknown causes [1]. CSU/CIU is thought to affect $0.5-1 \%$ of the global population at any given time, with CSU/CIU accounting for approximately two-thirds of all cases of chronic urticaria (CU) [2]. It has been estimated that 33-67\% of patients with CSU/CIU have both hives and angioedema, with 29-65\% having hives alone and 1-13\% angioedema alone [2]. Although the clinical features and pathogenesis of CSU/CIU have been well studied over the past decade [3], the humanistic and economic burden of CSU/CIU have not been elucidated in detail, specifically, in patients with an inadequate response to first-line therapies.

However, generally across all patient types, CSU/CIU can have a considerable burden on patients, healthcare systems and society. Moreover, the current standard of care, $\mathrm{H}_{1}$-antihistamines at licensed doses, is only effective at resolving symptoms in less than $50 \%$ of patients with CSU/CIU. Further increases in dose of $\mathrm{H}_{1}$-antihistamines does improve treatment response, but every third or fourth patient is thought to remain refractory (symptomatic despite treatment) [2], and may therefore have a higher burden of disease when compared to nonrefractory patients. The burden of disease is also particularly high in patients with CSU/CIU and associated angioedema, which, when compared to hives alone, can increase disease severity and duration [2]. In addition to the impact of the physical signs and symptoms, CSU/ CIU can also have a profound impact on the lives of patients due to factors such as sleep disruption, anxiety, embarrassment, depression and social isolation [2, 4-7]. Many aspects of daily activities (e.g., choice of clothes or going to the shops [8]) are also negatively impacted in patients with CSU/CIU [2]; and for those patients who are employed, impaired work performance or even absence from work are common [2, 9]. There is also a need to ensure timely and appropriate referral of patients with CSU/CIU to specialists in order to reduce delays in their diagnosis and the implementation of effective pharmacological management. This is especially true for those patients who are symptomatic despite on-going treatment with current standard of care. In many cases this need is not met, with patients seeing an average of more than two physicians before being referred to a specialist [10]. Reducing the burden associated with CSU/CIU therefore requires a broader understanding of the impact of these unmet needs of patients [2].
The guidelines recommend a stepwise approach in the management of $\mathrm{CSU}$, beginning with licensed doses of $\mathrm{H}_{1}$-antihistamines [1]. However, many patients remain uncontrolled and in these situations, current guidelines recommend increasing the dose by up to four-fold [1]. In patients non-responsive to higher doses of $\mathrm{H}_{1}$-antihistamines, guidelines recommend the addition of a third-line treatment option of omalizumab, ciclosporin or montelukast [1]. Among these third-line options, only omalizumab is currently approved as add-on therapy for the treatment of CSU/CIU in adult and adolescent ( $\geq 12$ years) patients showing an inadequate response to $\mathrm{H}_{1}$-antihistamine treatment.

Few studies have specifically evaluated the economic impact of CSU/CIU. In 2005, DeLong and colleagues estimated the total annual cost in the US as being $\$ 2047$ per patient, with indirect costs accounting for $15.7 \%$ (\$322) [9]. Another study analyzing 2002 data estimated the total annual cost in France as being $€ 2128$ per patient, with productivity costs accounting for $92.2 \%(€ 1962)$ [11]. Studies based on insurance claims cannot assess clinical aspects and patient perspectives because they lack recorded clinical data; it is also possible that the lack of specific International Classification of Diseases (ICD) code for CSU/CIU [12], may have resulted in an underestimated number of affected patients. As such, the true economic cost of CSU/CIU needs to include both direct costs, such as medication and costs of treatment, as well as indirect costs related to lack of productivity and absence from work.

Importantly, there are no studies which specifically evaluate the burden of disease in patients who are nonresponsive to standard-of care $\left(\mathrm{H}_{1}\right.$-antihistamines at licensed doses). The objective of ASSURE-CSU is to identify and quantify the humanistic, societal and economic burden of disease in patients with inadequately controlled CSU/CIU, with a focus on patients whose disease persists for $\geq 12$ months. This study will evaluate health-related quality-of-life (HRQoL) using patient-reported outcomes (PROs), healthcare resource utilization, absence from work and productivity loss among patients with CSU who are currently symptomatic despite treatment. This study, collecting real-world data in this patient population, will contribute to a better understanding of the impact of CSU/ $\mathrm{CIU}$ and its associated unmet need.

\section{Methods/design}

\section{Study design and participants}

ASSURE-CSU is an observational, multinational, multicenter study being conducted in seven countries (UK, Germany, Canada, France, Italy, Spain and The Netherlands). The study has two components: a retrospective medical chart review including patient medical- 
record abstraction and a patient survey that contains several validated PROs (Fig. 1). These measures will assess disease and dermatological quality of life (QoL), general health status, symptoms and also the impact of CSU/CIU on work and activities. Planned enrolment is approximately $700 \mathrm{CSU} / \mathrm{CIU}$ patients (approximately 100 patients from an average of 10 centers in each participating country) who are at least 18 years of age, are symptomatic despite current treatment, and have symptoms that have persisted for at least 12 months. Inclusion and exclusion criteria are detailed in Table 1.

\section{Objectives}

The primary objectives of the study are to describe patient demographic characteristics, medical history, treatments and healthcare resource utilization based on medical record data; as well as impact of disease, healthcare resource utilization, work days missed and productivity loss based on patient-reported data (Table 2).
Secondary objectives are to collect the following information from medical records and patient-reported data: number of patients receiving guideline recommended treatments (EAACI/GA ${ }^{2} \mathrm{LEN} / \mathrm{EDF} / \mathrm{WAO}$ [1]); diagnostic code or terminology used to identify CSU/CIU, as recorded in the medical records (e.g., chronic idiopathic/ chronic ordinary versus chronic spontaneous urticaria); treatment response as available in the medical record; disease severity and symptoms linked to medical resources; loss of productivity and impact on patients' HRQoL.

\section{Data collection}

Clinical staff in tertiary care review patient medical records and capture demographic, clinical, and healthcare resource data, to be extracted via a web-based electronic data capture application. Retrospective data are collected for the previous 12 months ( \pm 1 month) prior to study enrolment. The following data are collected: patient

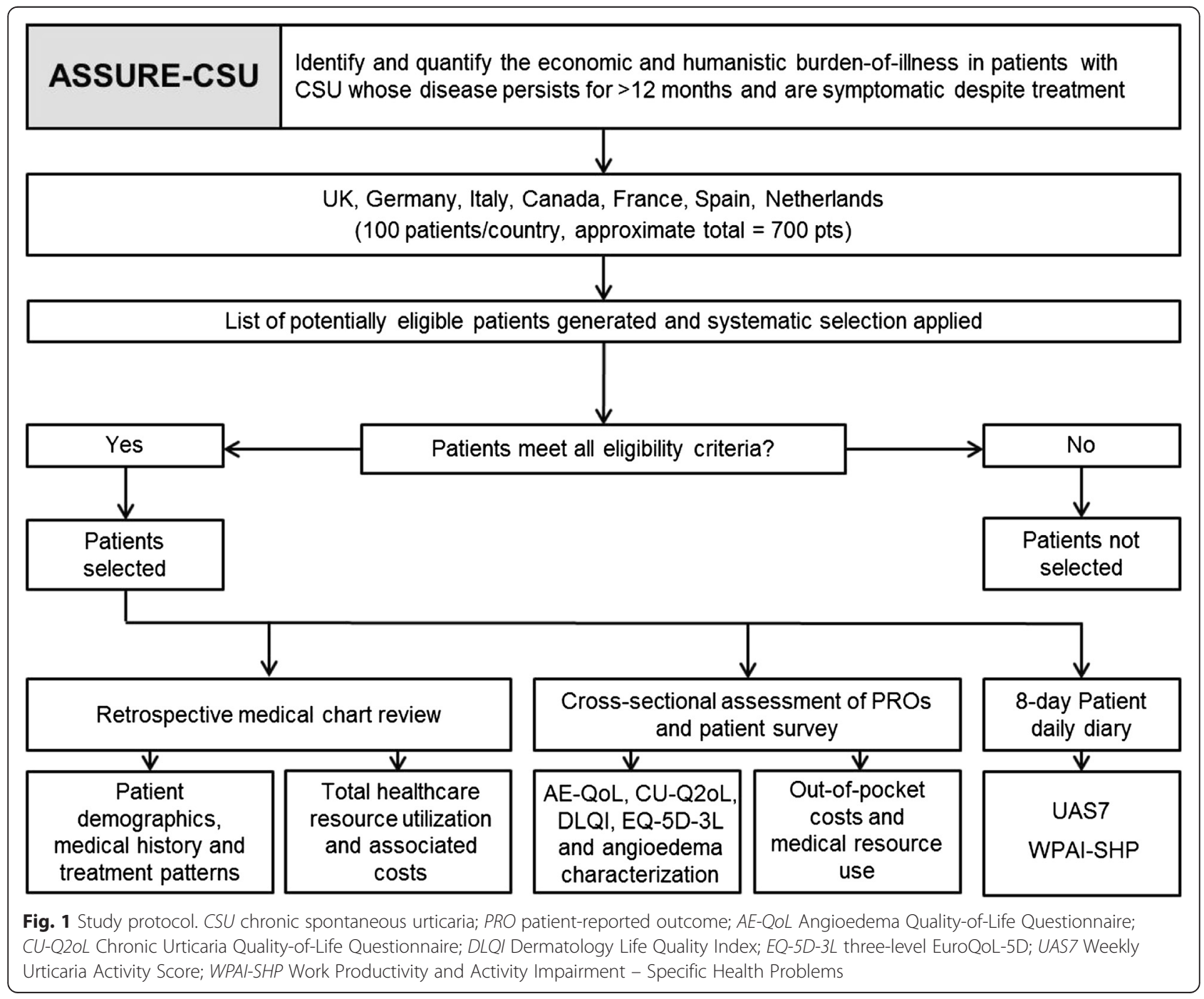


Table 1 Patient selection criteria in the ASSURE-CSU study

\begin{tabular}{|c|c|}
\hline Inclusion criteria & Exclusion criteria \\
\hline $\begin{array}{l}\text { - Clinician-confirmed diagnosis of CSU/CIU, defined as occurrence of } \\
\text { spontaneous hives and/or angioedema for at least } 6 \text { weeks without an } \\
\text { obvious cause }\end{array}$ & - Symptoms resolved within 12 months of diagnosis \\
\hline $\begin{array}{l}\text { - Symptomatic for more than } 12 \text { months at least } 3 \text { days per week and } \\
\text { currently symptomatic despite treatment }\end{array}$ & $\begin{array}{l}\text { - Determined to be in remission/resolved, defined as more than } 6 \text { months } \\
\text { untreated and without symptoms }\end{array}$ \\
\hline $\begin{array}{l}\text { - Under care of the participating site/physician for at least } 12 \text { months or } \\
\text { the participating site/physician has documentation of the patient's } \\
\text { relevant medical information (e.g., referral letters) for the } 12 \text { months } \\
\text { prior to enrolment }\end{array}$ & $\begin{array}{l}\text { - Urticaria is predominantly of the inducible form (i.e., physical, cholinergic); } \\
\text { however, patients with comorbid inducible urticaria may be included in the } \\
\text { study provided that it is of secondary importance to CSU/CIU }\end{array}$ \\
\hline $\begin{array}{l}\text { - Received at least one treatment course with an } \mathrm{H}_{1} \text {-antihistamine } \\
\text { (licensed dose) }\end{array}$ & $\begin{array}{l}\text { - Participated in a CSU/CIU interventional study or clinical trial during the } \\
\text { data collection period }\end{array}$ \\
\hline - Able to provide informed consent & - Unable to provide informed consent \\
\hline - Willing and able to complete the surveys & - Not able and not willing to complete the surveys \\
\hline Aged 18 years or older at the time of study enrolment & \\
\hline
\end{tabular}

CSU chronic spontaneous urticaria

demographics including age, gender, and ethnicity; baseline medical history including co-morbidities, duration and severity of CSU/CIU; treatments received for CSU/ CIU including duration and treatment response; healthcare resource utilization related to CSU/CIU, including the type and specialty of healthcare professional visited and frequency of visits and the number of emergency room visits. Further details of the estimation of direct and indirect costs are summarized in Table 3.

Patient-completed surveys and 8-day diaries collect information from all eligible patients. The crosssectional surveys capture information on healthcare resource utilization related to CSU/CIU and specifically angioedema, if applicable. This includes the number of patient-reported medical visits (not recorded in medical record charts), as well as out-of-pocket costs

Table 2 Primary assessments of the ASSURE-CSU study

\begin{tabular}{|c|c|}
\hline Medical record data & Patient-reported data \\
\hline \multirow[t]{5}{*}{ Demographic characteristics } & Impact of disease tools: \\
\hline & $\cdot$ EQ-5D-3L \\
\hline & • DLQI \\
\hline & • CU-Q2OL \\
\hline & $\begin{array}{l}\text { - AE-QoL (in patients } \\
\text { with angioedema) }\end{array}$ \\
\hline Baseline medical history & Angioedema history and characterization \\
\hline $\begin{array}{l}\text { Treatment received for } \\
\text { CSU/CIU }\end{array}$ & $\begin{array}{l}\text { Healthcare resource utilization (other than } \\
\text { that recorded in charts, use of alternative } \\
\text { medications and out-of-pocket expenses) }\end{array}$ \\
\hline Duration of treatments & Disease activity (UAS7) \\
\hline $\begin{array}{l}\text { Total healthcare resource } \\
\text { utilization }\end{array}$ & $\begin{array}{l}\text { Work days and productivity loss } \\
\text { (WPAl-SHP) }\end{array}$ \\
\hline
\end{tabular}

EQ-5D-3L three-level EuroQoL-5D, DLQ/ Dermatology Life Quality Index, CU-Q2oL Chronic Urticaria Quality-of-Life Questionnaire, AE-QoL Angioedema Quality-of-Life Questionnaire, CSU chronic spontaneous urticaria, UAS7 Weekly Urticaria Activity Score, WPAl-SHP Work Productivity and Activity Impairment - Specific Health Problems including transportation/parking costs. Impact of disease will be assessed using four validated PROs: the Dermatology Life Quality Index (DLQI), Chronic Urticaria Quality-of-Life Questionnaire (CU-Q2oL), three-level EuroQoL-5D (EQ-5D-3L) and, in patients with angioedema, the Angioedema Quality-of-Life Questionnaire

Table 3 Evaluation of direct and indirect costs associated with CSU

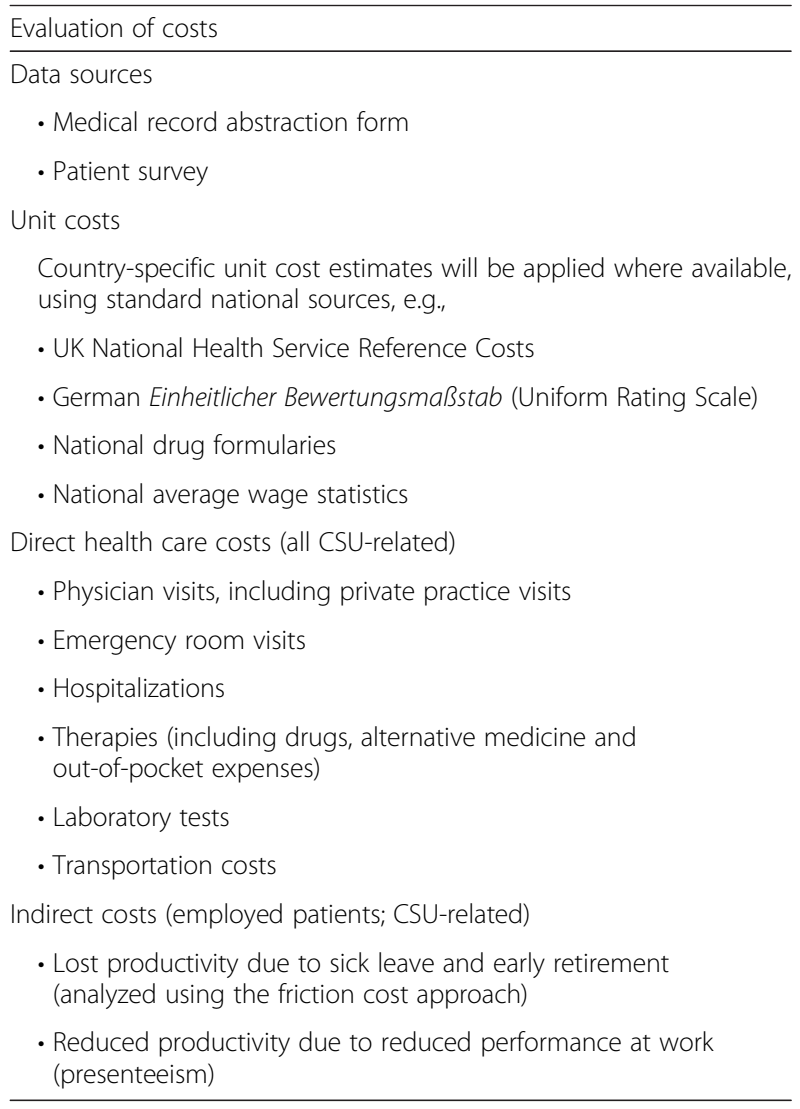

CSU chronic spontaneous urticaria 
(AE-QoL). The DLQI is designed for use in patients with dermatological disorders and is not specific to CSU/CIU, but has been used previously across a number of dermatologic diseases (including CSU/CIU) and measures overall impact on HRQoL in such dermatological conditions $[13,14]$. It has a seven day recall period and scores from 0 to 30 with higher score meaning higher impact and lower QoL.

The CU-Q2oL, which measures various aspects of chronic urticaria specific QoL impairment [15], has a two week recall period and a score from 0 to 100, with higher score indicating higher QoL impairment.

The EQ-5D-3L is a generic tool that is used to measure health status in a wide variety of diseases $[16,17]$. It assesses the impact of disease in that day and allows the calculation of a utility score ranging from 0 (death) to 1 (perfect health).

The AE-QoL assesses the impact of angioedema on patient QoL [18]. In addition the angioedema survey allows a description of angioedema episodes with their frequency, localization, symptoms and duration.

The patient diary collects seven days of information on disease activity using the Urticaria Activity Score (UAS) and on day 8 , work absence and productivity information using the Work Productivity and Activity Impairment-Specific Health Problems (WPAI-SHP) questionnaire. The UAS is a validated diary-type tool that daily assesses disease activity through the severity of symptoms (hives and itch) [19]. It is usually scored over a period of seven days to give the weekly UAS score (UAS7) ranging from 0 to 42, with higher scores indicating greater disease severity [20]. The validity and reproducibility of the WPAI-SHP questionnaires are well established in a number of specific diseases (including the dermatological condition chronic hand dermatitis) [21]. This questionnaire captures absence from work (absenteeism), reduced productivity while at work (presenteeism), overall activity impairment and has a recall period of seven days.

\section{Data analyses}

All study results will be summarized descriptively for each country (apart from direct and indirect costs which will estimated for each country using validated local sources) and for the pooled population across all countries. This includes a tabular display of mean values, medians, ranges, standard deviations for continuous variables of interest and frequency distributions for categorical variables. Results will be stratified by disease severity as measured by the UAS7 score.

For data on healthcare resource utilization, costs will be calculated for items by estimated unit costs for each resource per country. All cost data will be inflated to the most current cost year (2013/4) and adjusted to the currency value for each country where appropriate. Indirect costs will be estimated using the WPAI results for employed patients only, which uses an algorithm relevant for each country, based on average number of weekly hours worked and the hourly country-specific wage. The total indirect cost, presented also as overall work impairment cost, incorporates both absenteeism and presenteeism related costs.

In addition to descriptive statistical summaries of study results, where appropriate, multivariate analyses may be conducted to assess the differences in resource utilization and cost outcomes between levels of disease severity.

\section{Discussion}

Currently available literature points to a significant humanistic and economic burden for patients with CSU/ $\mathrm{CIU}$ as well as considerable demands on healthcare resources $[2,5-7,9]$. As up to $50 \%$ of patients do not fully respond to currently recommended first-line therapy $\left(\mathrm{H}_{1}\right.$-antihistamines at licensed doses) [2], further analysis is required to fully understand the disease burden in this particular subgroup of patients. ASSURE-CSU is the first study to address this unmet need. Its design will allow collection of medical resource utilization data and patient perspectives on a disease with an unrecognized burden. A better understanding of patient journey, time between onset, diagnosis and management will hopefully result in an optimized approach to patient management.

ASSURE-CSU does have some limitations which can be listed. Firstly, the study is only for patients with CSU/ CIU who are symptomatic despite treatment with current standard of care ( $\mathrm{H}_{1}$-antihistamines at licensed doses). Results are obtained from large treatment centers within each participating country, as such, information on patients who are not currently being treated or that are being treated by an office-based dermatologist/allergist will not be captured. Furthermore, it should be noted that patients may be symptomatic due to additional factors such as poor treatment compliance, under-treatment or treatment which has not been optimized for the patient.

The quantity and quality of the data obtained by medical record abstraction will be dependent on availability and accuracy of the data in the physicians' records (e.g., duration of treatment, type of therapies or the relative success of previous treatments). As only 12 months of retrospective data are collected, a full picture of the patient since diagnosis is not obtained. A record of patient symptoms is collected prospectively for seven days using the UAS but this will only provide a snapshot of disease severity related to the UAS7 score of the representative week; this is particularly important to note, as disease severity can vary, and symptoms resolve over time.

Finally, although the ASSURE-CSU study has a broad number of objectives, because of its cross-sectional 
approach, it will not provide data on patient follow-up, natural disease history, natural remission rates, prevalence of $\mathrm{CU}$ or CSU/CIU, proportion of refractory patients, or proportion of responders to each therapy (within a country or globally). Neither will information on those patients who have $\mathrm{H}_{1}$-antihistamine-responsive CSU be collected, as they are outside of the focus of this analysis.

As far as we are aware, ASSURE-CSU will be the first international multicenter study to examine the economic and humanistic burden of disease on patients who are symptomatic despite current recommended first-line therapy. By using a combination of retrospective (patient medical-record abstraction) and prospective (patient surveys and 7-day diary) analysis across seven different countries, the ASSURE-CSU study can increase the understanding of the impact of CSU/CIU on patients and the associated costs. ASSURE-CSU will inform us of the patient journey, the potential success of management for refractory CSU/CIU and also possible ways to improve the perspectives that different stakeholders have on this disease. The study has been completed in five countries and data collection in the remaining countries is planned to be completed by the end of April 2015.

\begin{abstract}
Abbreviations
ASSURE-CSU: Assessment of the economic and humanistic burden of chronic spontaneous/idiopathic urticaria patients; AE-QoL: Angioedema Quality-of-Life Questionnaire; CIU: Chronic idiopathic urticaria; CSU: Chronic spontaneous urticaria; CU-Q2oL: Chronic Urticaria Quality of Life Questionnaire: DLQI: Dermatology Life Quality Index; EQ-5D-3L: three-level EuroQoL-5D; PRO: Patient-reported outcomes; UAS7: Weekly Urticaria Activity Score; WPAI-SHP: Work Productivity and Activity Impairment - Specific Health Problems.
\end{abstract}

\section{Competing interests}

KW was recently a speaker, investigator and/or advisor for Novartis, RTI, Uriach, FAES, UCB, MSD, Shire, Viropharma, Biocryst and MOXIE. MM has received grant, research or clinical trial support from Novartis, Genentech, Uriach, Abbott Laboratories, FAES, UCB and Moxie. He has acted as a consultant/participated in advisory board meetings for Novartis, Genentech, Uriach, Abbott Laboratories, FAES, MSD, Almirall, UCB and Sanofi. CG has participated in an advisory board for Novartis, was a principal investigator for a Novartis supported study and has received honoraria for Novartis supported meetings.

AN has received honoraria from Novartis for participation in advisory board Meetings in 2014. MA is a member of the Coeliac Disease Guidelines Development Group with N.I.C.E.. FB has served as an advisor or consultant for Merck Serono and Novartis Pharmaceuticals Corporation. GS has acted as a consultant for Novartis and in the past three years, he has conducted studies for Novartis, CSL Behring, Merck, and DBV Technologies. AG-A has acted as a medical advisor for Uriach Pharma, Genentech, Novartis; has received research grants from Intendis-Bayer, Uriach Pharma and Novartis and has participated in educational activities sponsored by Uriach Pharma, Novartis, Genentech, Menarini, GSK, MSD and Almirall. JOF has received payment from Novartis for participation in advisory board meetings and speaker presentations. AK has received payment from Novartis for participation in advisory boards, presentations and financial contribution to research projects. GWC has received payment for participation in Advisory Boards and Speaker Presentation for Novartis. $\mathrm{KH}$ and DMcB are employed by RTI Health Solutions, which provides consulting and other research services to pharmaceutical, device, government, and non-government organizations. In this salaried position, they work with a variety of companies and organizations. They receive no payment or honoraria directly from these organizations for services rendered. M-MB is an employee of Novartis Pharma AG.

\section{Authors' contributions}

M-MB and KH are study leads for ASSURE-CSU. M-MB conceived the study, participated in its design, development of the study protocol, and co-ordination of the study. $\mathrm{KH}$ and DMcB participated in the design, development of the study protocol, co-ordination and execution of the study. KW, MM, CG, AN, MA, FB, GS, AGA, JOF, AK and GWC participated in the design of the study, the co-ordination of the study, the recruitment of patients and data collection. All authors contributed to data interpretation. All authors contributed to the preparation and revision of this manuscript. All authors read and approved the final manuscript.

\section{Acknowledgements}

We thank Christine Radder (RTI Health Solutions, USA) for her assistance in data analysis. Editorial assistance was provided by Alex Goonesinghe, a professional medical writer contracted to CircleScience, an Ashfield Company, part of UDG Healthcare plc. Writing support was funded by Novartis Pharma AG.

\section{Funding}

This study is sponsored by Novartis Pharma AG, Basel, Switzerland.

\section{Author details}

${ }^{1}$ Allergie-Centrum-Charité, Department of Dermatology and Allergy, Charité - Universitätsmedizin Berlin, Charitéplatz 1, D-10117 Berlin, Germany. ${ }^{2}$ Dermatology Centre, Norfolk and Norwich University Hospital, Norwich, UK. ${ }^{3}$ Allergy and Immunology Clinic, Royal Liverpool and Broadgreen University Hospital, Liverpool, UK. ${ }^{4}$ Clinical Immunology and Allergology, CH Lyon-Sud, Claude Bernard University Lyon I - Faculty of Medicine, Lyon Sud, Lyon, France. ${ }^{5}$ Gordon Sussman Clinical Research Inc. 202 St Clair Avenue West, Toronto, Canada. ${ }^{6}$ Dermatology Department, Hospital del Mar, Institut Mar d'Investigacions Mèdiques, Universitat Autònoma, Barcelona, Spain. ${ }^{7}$ Hospital Universitario 12 de Octoubre, Dermatology Department, Madrid, Spain. ${ }^{8}$ Department of Dermatology and Allergy, UMC, Utrecht, The Netherlands. ${ }^{9}$ University of Genoa, San Martino-IST, Genoa, Italy. ${ }^{10}$ RTI Health Solutions, Raleigh, NC, USA. ${ }^{11}$ RTI Health Solutions, Manchester, UK. ${ }^{12}$ Novartis Pharma AG, Basel, Switzerland.

Received: 27 April 2015 Accepted: 30 June 2015

Published online: 17 August 2015

\section{References}

1. Zuberbier T, Aberer W, Asero R, Bindslev-Jensen C, Brzoza Z, Canonica GW, et al. The EAACI/GA²LEN/EDF/WAO Guideline for the definition, classification, diagnosis and management of Urticaria. The 2013 revision and update. Allergy. 2014;69:868-87.

2. Maurer M, Weller K, Bindslev-Jensen C, Giménez-Arnau A, Bousquet PJ, Bousquet J, et al. Unmet clinical needs in chronic spontaneous urticaria. A GA²LEN task force report. Allergy. 2011;66:317-30.

3. Saini SS. Chronic spontaneous urticaria: etiology and pathogenesis. Immunol Allergy Clin North Am. 2014;34:33-52.

4. O'Donnell BF, Lawlor F, Simpson J, Morgan M, Greaves MW. The impact of chronic urticaria on the quality of life. Br J Dermatol. 1997;136:197-201.

5. Kang MJ, Kim HS, Kim HO, Park YM. The impact of chronic idiopathic urticaria on quality-of-life in Korean patients. Ann Dermatol. 2009;21:226-9.

6. Engin B, Ozdemir M. Prospective randomized non-blinded clinical trial on the use of dapsone plus antihistamine vs. antihistamine in patients with chronic idiopathic urticaria. J Eur Acad Dermatol Venereol. 2008;22:481-6.

7. Barbosa F, Freitas J, Barbosa A. Chronic idiopathic urticaria and anxiety symptoms. J Health Psychol. 2011;16:1038-47.

8. Finlay AY, Khan GK. Dermatology Life Quality Index (DLQI)-a simple practical measure for routine clinical use. Clin Exp Dermatol. 1994;19:210-6.

9. Delong LK, Culler SD, Saini SS, Beck LA, Chen SC. Annual direct and indirect health care costs of chronic idiopathic urticaria: a cost analysis of 50 nonimmunosuppressed patients. Arch Dermatol. 2008;144:35-9.

10. Weller K, Schoepke N, Krause K, Ardelean E, Bräutigam M, Maurer M. Selected urticaria patients benefit from a referral to tertiary care centres-results of an expert survey. J Eur Acad Dermatol Venereol. 2013;27:e8-16.

11. Kapp A, Demarteau N. Cost effectiveness of levocetirizine in chronic idiopathic urticaria: a pooled analysis of two randomised controlled trials. Clin Drug Investig. 2006;26:1-11. 
12. World Health Organization. International statistical classification of diseases and related health problems: 10th revision (ICD-10). 2015. http://apps.who.int/ classifications/icd10. Accessed 23 April 2015.

13. Lennox RD, Leahy MJ. Validation of the Dermatology Life Quality Index as an outcome measure for urticaria-related quality of life. Ann Allergy Asthma Immunol. 2004;93:142-6.

14. Shikiar R, Harding G, Leahy M, Lennox RD. Minimal important difference (MID) of the Dermatology Life Quality Index (DLQI): results from patients with chronic idiopathic urticaria. Health Qual Life Outcomes. 2005;3:36.

15. Baiardini I, Pasquali M, Braido F, Fumagalli F, Guerra L, Compalati E, et al. A new tool to evaluate the impact of chronic urticaria on quality of life: chronic urticaria quality of life questionnaire (CU-QoL). Allergy. 2005;60:1073-8.

16. EuroQoL Group. EuroQoL-a new facility for the measurement of healthrelated quality of life. Health Policy. 1990;16:199-208.

17. Brooks R. EuroQol: the current state of play. Health Policy. 1996;37:53-72.

18. Weller K, Groffik A, Magerl M, Tohme N, Martus P, Krause K. Development and construct validation of the angioedema quality of life questionnaire. Allergy. 2012;67:1289-98.

19. Mlynek A, Zalewska-Janowska A, Martus P, Staubach P, Zuberbier T, Maurer M. How to assess disease activity in patients with chronic urticaria? Allergy. 2008:63:777-80.

20. Mathias SD, Crosby RD, Zazzali JL, Maurer M, Saini SS. Evaluating the minimally important difference of the urticaria activity score and other measures of disease activity in patients with chronic idiopathic urticaria. Ann Allergy Asthma Immunol. 2012;108:20-4.

21. Reilly MC, Zbrozek AS, Dukes EM. The validity and reproducibility of a work productivity and activity impairment instrument. Pharmacoeconomics. 1993:4:353-65.

\section{Submit your next manuscript to BioMed Central and take full advantage of:}

- Convenient online submission

- Thorough peer review

- No space constraints or color figure charges

- Immediate publication on acceptance

- Inclusion in PubMed, CAS, Scopus and Google Scholar

- Research which is freely available for redistribution 